\title{
Library-Authored Web Content and the Need for Content Strategy
}

\section{ABSTRACT}

Increasingly sophisticated content management systems (CMS) allow librarians to publish content via the web and within the private domain of institutional learning management systems. "Libraries as publishers" may bring to mind roles in scholarly communication and open scholarship, but the authors argue that libraries' self-publishing dates to the first "pathfinder" handout and continues today via commonly used, feature-rich applications such as WordPress, Drupal, LibGuides, and Canvas. Although this technology can reduce costly development overhead, it also poses significant challenges. These tools can inadvertently be used to create more noise than signal, potentially alienating the very audiences we hope to reach. No CMS can, by itself, address the fact that authoring, editing, and publishing quality content is both a situated expertise and a significant, ongoing demand on staff time. This article will review library use of CMS applications, outline challenges inherent in their use, and discuss the advantages of embracing content strategy.

\section{INTRODUCTION}

We tend to look at content management as a digital concept, but it's been around for as long as content. For as long as humans have been creating content, we've been searching for solutions to manage it. The Library of Alexandria (300 BC to about AD 273) was an early attempt at managing content. It preserved content in the form of papyrus scrolls and codices, and presumably controlled access to them. Librarians were the first content managers. ${ }^{1}$ (emphasis added)

Content is, and has always been, central to the mission of libraries. Content is physical, digital, acquired, purchased, leased, subscribed, and created. "Libraries as publishers" may bring to mind roles in scholarly communication and open scholarship, but the authors argue that libraries' selfpublishing dates to the first mimeographed 'pathfinder' handout and continues today via commonly used, feature-rich web content management systems (CMSs). Libraries use these CMSs to support research, teaching, and learning in a variety of day-to-day operations.

The sophisticated and complex infrastructure surrounding web-based library content has evolved from the singular, independently hosted and managed "library website" into a "library web ecosystem" comprised of multiple platforms, including integrated library systems, institutional repositories, CMSs, and others. Multiple CMS applications, whether open-source (e.g., WordPress, Drupal), institutionally supported (e.g., Canvas, Blackboard) or library-specific (e.g., Springshare's LibGuides), are employed by most libraries to power the library's website and research guides, as well as to make their collections, in any and all formats, discoverable and accessible.

Courtney McDonald (crmcdonald@colorado.edu) is Learner Experience \& Engagement Librarian and Associate Professor, University of Colorado at Boulder. Heidi Burkhardt (heidisb@umich.edu) is Web Project Manager \& Content Strategist, University of Michigan. 
Library staff at all levels create and publish content through these CMS platforms, an activity that is critical to our users discovering what we offer and accomplishing their goals. The CMS removes technical bottlenecks and enables subject matter experts to publish content without coding expertise or direct access to a server. This disintermediation has many benefits, enabling librarians to share and interact directly with their communities, and reducing costly development overhead.

As with any powerful technology that's simple to use, effectively implementing a CMS is not without pitfalls. Through these tools, we can inadvertently create more noise than signal, potentially alienating the very audiences we hope to reach. Further, effective management of content and workflows across and among so many platforms is not trivial. Distributing web content creation among many authors can quickly lead to numerous challenges requiring expert attention. Governance strategies for library-authored web content are rarely addressed in the library literature.

This article will review library use of CMS applications, outline challenges inherent in their use, and discuss the advantages of embracing content strategy as a framework for library-authored web content governance.

\section{CONTENT MANAGEMENT SYSTEMS: A DEFINITION}

Any conversation on this topic is complicated by the fact that there is both misunderstanding and disagreement regarding the definition of a content management system.

In their survey of 149 libraries covering day-to-day website management, including staffing, infrastructure, and organizational structures, Bundza et al. observed "[w]hen reviewing the diverse systems mentioned, it is obvious that people defined CMSs very broadly." ${ }^{2}$ Connell surveyed over 600 libraries regarding their use of CMSs, defined as "website management tools through which the appearance and formatting is managed separately from content, so that authors can easily add content regardless of web authoring skills." ${ }^{3} \mathrm{~A}$ few respondents "indicated their CMS was Dreamweaver or Adobe Contribute" and another "self-identified as a non-CMS user but then listed Drupal as their web management tool."4 While the authors find the survey definition itself slightly ambiguous (likely in the service of clarity for survey respondents), we also believe that these responses may hint at an underlying and widespread lack of clarity regarding the technology itself.

An early report on potential library use of content management systems by Browning and Lowndes in 2001 opined that "a CMS is not really a product or a technology. It is a catch-all term that covers a wide set of processes that will underpin the 'Next Generation' large-scale website." ${ }^{5}$ While technological developments over the last twenty years reveal some limitations to this early characterization, we believe it is fundamentally sound to define the CMS primarily through its functions.

Fulton defined a CMS as "an application that enables the shared creation, editing, publishing, and management of digital content under strict administrative parameters." ${ }^{6}$ The authors concur with Barker's (2016) similarly task-based definition: "A content management system (CMS) is a software package that provides some level of automation for the tasks required to effectively manage content ... usually server-based, multi-user ... [and] interact[ing] with content stored in a 
repository." ${ }^{77}$ Browning \& Lowndes defined the key tasks, or functions, of the CMS as encompassing four major categories: Authoring, Workflow, Storage, and Publishing. ${ }^{8}$

Barker (2016) also outlined "the big four" of content management as: enterprise content management (e.g., intranets), digital asset management (DAM), records management, and web content management (WCM), with WCM defined as "the management of content primarily intended for mass delivery via a website. WCM excels at separating content from presentation and publishing to multiple channels." ${ }^{\prime 9}$ For the purpose of clarity within the scope of this article, our discussion will primarily focus on content management systems as they are used for WCM, acknowledging that some principles may apply in varying degrees to other categories.

\section{THE CMS AND LIBRARY WEBSITES}

The library literature reveals that, generally speaking, libraries began the transition from telnet and Gopher catalog interfaces to launching websites in the $1990 \mathrm{~s} .{ }^{10}$ Case studies of library websites from this period through the mid-2000s report library website pages increasing at a rapid rate, in some cases doubling or tripling on a yearly basis. ${ }^{11} \mathrm{~A}$ comment from Dallis and Ryner in regard to their own case study provides a sense of what might be considered typical during this period: "The management of the site was decentralized, and it grew to an estimated 8,000 pages over a period of five years." 12

This proliferation, in turn, spurred focused interest in content management. "Web content management (WCM) as a branch of content management (CM) gained importance during the Web explosion in the mid-1990s."13 As early as 2001 there were published laments regarding the state of library websites:

Institutions are struggling to maintain their Web sites. Out of date material, poor control over design and navigation, a lack of authority control and the constriction of the Webmaster (or even Web Team) bottleneck will be familiar to many in the HE/FE [Higher Education / Further Education] sector.

The pre-millennial Web has been characterized by highly manual approaches to maintenance; the successful and sustainable post-millennial Web will have significant automation. One vehicle by which this can be achieved is the CMS. ${ }^{14}$

Mach wrote:

The special concerns of Web maintenance have only multiplied with the increased size and complexity of many library Web sites. Not only does the single Webmaster model no longer work for most libraries, but the static HTML page is also in jeopardy. Many overworked Web librarians dream about the instant content updates possible with database-driven site or content management software. But while these technical solutions save staff time, they demand a fair amount of compromise. ${ }^{15}$

In 2010, Fulton noted, "at one time, all institutions [mentioned in her literature review] could effectively manage their sites outside of a CMS. However, changing standards combined with uncontrollable growth patterns persuaded them to take steps to prevent prolonged chaos." ${ }^{16}$ 


\section{Changing Technology, Accessibility, and Literacy}

Throughout the early 2000s, advances in consumer technology and in web development (e.g., CSS, HTML 5, Bootstrap) together with the need to comply with web-accessibility standards resulted in a gradual move from static, hand-coded sites to other solutions. In 2005, Yu stated, "Today's content management solution is either a sophisticated software-based system or a databasedriven application." ${ }^{17}$ After a detailed explanation of the cumbersome process of managing and updating a static site using Microsoft's FrontPage, Kane and Hegarty noted, "The opportunity to migrate the site to a content management system provided a golden opportunity ... to bring the code into line with best practice." 18 This transition also coincided with the growth of viable CMS options, particularly open-source tools. Black stated in 2011: "In the past few years, the field of open-source CMSs has increased, making it more likely that a library will find a viable CMS in the existing marketplace that will meet the organization's needs."19

In 2013, Comeaux and Schmetzke replicated an earlier study of library websites' accessibility, reviewing the homepages of library websites at 56 institutions offering ALA-accredited library and information science programs using Bobby, an automated web-accessibility checker. They found that CMS-powered library websites had a higher average of approved pages and a lower average of errors per page than those not powered by a CMS. ${ }^{20}$ In a 2017 study, Comeaux manually reviewed 37 academic library websites (members of the Association of Southeastern Research Libraries), and found that approximately three-quarters of CMS-driven sites were responsive, as compared to only one-quarter of sites without a CMS. ${ }^{21}$

Accessibility also manifests itself on the web in other ways. It is important to consider what we know about literacy and how people read online. The ability to write using plain language, in addition to other essential techniques for effective web writing, is an important aspect of accessibility that must be addressed in tandem with compliance with industry standards such as the Web Content Accessibility Guidelines (WCAG, https://www.w3.org/TR/WCAG20/). A summary of recent results for the Program for the International Assessment of Adult Competencies (PIAAC, https://nces.ed.gov/surveys/piaac/) survey, administered to US adults, reported "the majority of people may struggle to read through a 'simple' bullet-point list of rules ... Nearly $62 \%$ of our population might not be able to read a graph or calculate the cost of shoes reliably." ${ }^{22}$ Blakiston succinctly observed: "on the web, scanning and skimming is the default."23

These trends have led to an increasing push to adopt "plain language" by governmental agencies and others. ${ }^{24}$ Skaggs stated, "Adopt plain language throughout your website. Plain language focuses on understanding and writing for the user's goals, making content easily scannable for the user, and writing in easy to understand sentences." 25

\section{LIBRARY WEBSITES AND THE CHALLENGES OF A DISTRIBUTED ENVIRONMENT}

In 2011, Black pointed out one of the chief advantages to using a CMS: “CMSs support a distributed content model by separating the content from the presentation and giving the content provider an easy to use interface for adding content". ${ }^{26}$ Empowerment to focus on special expertise is noted as another benefit: "Chief among the efficiencies gained in using a CMS is the simple act of giving content authors the tools they need to create webpages and, most importantly, to do so without requiring the technical knowledge that used to be a part of webpage development. Designers can design, writers can write, editors can edit, and technology folks can manage the CMS and support 
its users."27 Browning and Landes agreed: "the concept of 'self-service authoring', whereby staff do not need special skills to edit the content for which they are responsible, can be regarded as a major step towards acceptance of the web as a medium for communication by non-web specialists. Providing this is the key advantage of a CMS." ${ }^{28}$

Librarians quickly found, however, that while the adoption of a CMS could empower more subject matter experts to participate in web content development and address technical issues such as responsive design and compliance with accessibility standards, the transition to a distributed model of content creation, oversight, and maintenance resulted in larger organizational ramifications. In 2006, approximately a decade following libraries' general move to the web and at an early stage for CMS adoption, Guenther (2006) cautioned: "A CMS is only a tool. Purchasing the very best CMS with every bell and whistle available will be a useless exercise without a solid plan to guide people and processes around its use."29 This same article went on to observe:

What makes using a CMS a tremendous advantage is exactly what makes it a potential nightmare. A CMS can make website development really easy; that's the good part. The bad part is, it makes webpage development really easy. One of the first issues you encounter is having to suddenly support a lot more content authors posting a lot more content. What once was an environment with limited activity can become a web development environment requiring considerably more oversight and technical support. Having more hands stirring the pot, so to speak, is wrought with all kinds of challenges. ${ }^{30}$

\section{Untenable Growth}

This model of distributed content creation, in which authorship is undertaken by numerous parties across the organization, generally results in a rapidly increasing quantity of content without necessarily guaranteeing consistent quality.

A review of the literature reveals that, more commonly, a distributed model leads to a lack of consistency and focus in library web content's structure and execution. Some papers underscore the problematic quality of the highly individualized nature of the content: "the sheer mass of [libraries'] public web presence has reached the point where maintenance is a problem. Often the webpages grew out of the personal interests of staff members, who have since left for other jobs for other responsibilities or simply retired." ${ }^{31}$

Blakiston stated, "For a number of years, librarians were motivated to create more web content. It was assumed that adding more content was a service for library users, and it was also seen as a way to improve their web skills and demonstrate their fluency with technology." ${ }^{2}$ Similarly, Chapman and Demsky described how the University of Michigan Library website grew "in an organic fashion" and noted, "[a]s in many places, the library's longstanding attitude toward the web was that more was more and that there was really no harm in letting the website develop however individual units and librarians thought best." 33

Other papers described "authority and decision-making issues ... differing opinions, turf struggles or a lack of communication ... a shortage of time and motivation, general inertia, and resistance to change on the part of content authors." ${ }^{44}$ Iglesias noted, "Some librarians will always be more comfortable creating webpages from scratch, fearing a loss of control. The library as a whole must decide if the core responsibility of librarians is to create content or to create websites." ${ }^{35}$ 
Newton and Riggs stated, "This approach to content appears to be at odds with the role of librarians as leaders in information management practices and in supporting users to find, filter and critically evaluate information." ${ }^{36}$ In her article "Editorial and Technological Workflow Tools to Promote Website Quality," Morton-Owens discussed several studies measuring the severe impact of even small flaws (such as typographical errors) on users' judgements of a website's credibility, and, by extension, of the organization's credibility: "users' experience of a website leads them to attribute characteristics of competence and trustworthiness to the sponsoring organization." 37

A. Paula Wilson, citing McConnell and Middleton, summarized the potential pitfalls inherent in a distributed model in which empowerment of content creators overshadows a unified vision, strategy, and approach to library-wide content management:

A decentralized model without the use of guidelines, standards or templates will eventually fail. The website may experience inconsistency in presentation and navigation, outdated and incorrect information, and gaps in content, and its webpages maybe noncompliant in usability and accessibility design so much so that users cannot find information. ${ }^{38}$

\section{Inconsistent Voice and Lack of Organizational Unity}

In addition to such compounding factors and in contrast to journalistic practice, "libraries lack an editorial culture where content production and management is viewed as a collective rather than a personal effort." ${ }^{39}$ Morton-Owens noted: "The concept of editing is not yet consistently applied to websites unless the site represents an organization that already relies on editors (like a newspaper)-but it is gaining recognition as a best practice. If the website is the most readily available public face of an institution, it should receive editorial attention just as a brochure or fundraising letter would." 40

In an environment with distributed authorship lacking a strong and consistent editorial culture, an organization's "voice" can quickly deteriorate. In web writing, voice is often defined as personality. Blakiston stated: "The written content you provide plays an essential role in defining your library as an organization." ${ }^{41}$ Young went further, aligning voice with values, and arguing "[a]ny item of content that your library creates - an FAQ, a policy page, or a Facebook post - should be conveyed in the voice of your library and should communicate the values of your library. A combined expression of content and values defines the voice of your organization." 42

In their 2006 article "CMS/CMS: Content Management System/Change Management Strategies," Goodwin et al. insightfully explore organizational challenges:

The effort of developing a unified web presence reveals where the organization itself lacks unity ... Effective use of a content management system requires an organized and comprehensive consolidation of library resources, which emphasizes the need for a different organizational model and culture-one that promotes thinking about the library as a whole, sharing and collaboration. ${ }^{43}$

Fulton built on this concept: "Disunity in the library's web interface could signify disunity within the institution. On the other hand, a harmonious web presence suggests an institution that works well together." 44 Young drew an inherent connection between a strongly unified organizational identity and a consistent and coherent "content strategy": 
While libraries in general can draw on decades or centuries of cultural identity, each individual library may wish to convey a unique set of attributes that are appropriate for unique contexts. In this way, the element of "organizational values" inherent to content strategy signals a larger visioning project for determining the mission, vision, and values of your library. If these elements are already in place, then the work of content strategy can easily be adapted to fit existing values statements. Otherwise, content strategy and organizational values can develop as a joint initiative. ${ }^{45}$

\section{LIBRARY WEBSITES AND CONTENT STRATEGY}

Content strategy is an emerging discipline that brings together concepts from user experience design, information architecture, marketing, and technical writing. Content strategy encompasses activities related to creating, updating, and managing content that is intentional, useful, usable, well-structure, easily found, and easily understood, all while supporting an organization's strategic goals. ${ }^{46}$

Browning and Lowndes recognized as early as 2002 that strategy would be required as the variety of communication channels for libraries increased: "As local information systems integrate and become more pervasive, self-service authoring extends to the concept of 'write once, re-use anywhere', in which the web is treated as just another communication channel along with email, word processor files and presentations, etc." ${ }^{47}$ More than a decade later, in the introductory column to a 2013 themed issue of Information Outlook focused on content strategy, Hales stated:

Content strategy is a field for which information professionals and librarians are ideally suited, by virtue of both their education and temperament. Content, after all, is another word for information, and librarians and information professionals have been developing strategies for acquiring, managing, and sharing information for centuries. Today, however, information is available to more people in more forms and through more channels than ever before, making content strategies a necessity for organizations rather than an afterthought. ${ }^{48}$

Jones and Farrington posited a common refrain for stating the importance of content strategy for librarianship: "Library website content must be viewed in much the same way as a physical collection" and the "library website, to apply S. R. Ranganathan's Fifth Law, is a growing organism and must be treated as such, especially with the complexity of web content." 49 Claire Rasmussen drew connections between Ranganathan's Laws and content strategy in a blog post, pointing out that web content represents an additional set of responsibilities to be managed: "For hundreds of years, librarians have been the primary caretakers of the content corpus. But somebody needs to care for the content that never makes it into a library's collections, too." 50

Blakiston \& Mayden provided a helpful overview of content strategy and its application in libraries in their article "How We Hired a Content Strategist (And Why You Should Too)," finding many points of connection between skill sets essential to content strategy and those commonly possessed by librarians:

Librarians who have worked in public services may have the needed skills to ask good questions and find out what users need ... professionals doing this kind of work came from backgrounds including communications, English and library science ... desirable 
qualifications for ... content strategist[s] ... [include] strategic planning, web skills and project management. ${ }^{51}$

The circumstances that motivated them to propose and eventually hire a dedicated content strategist at the University of Arizona Libraries hearken back to the discussion earlier in this article regarding the increasing complexity of web librarianship: "the web product manager had independently coordinated all user research and content strategy work. The idea of both managing [a major web redesign project] and leading these other important areas was not realistic." 52

Datig also pointed to increasing day-to-day responsibilities when advocating for the importance of content strategy for librarians with outreach and marketing responsibilities: "Lack of time, and a desire for that time to be well spent, is a huge concern for all librarians involved in library outreach and marketing ... content strategy is an important and overlooked aspect of maintaining an effective and vital library outreach program." ${ }^{53}$ Hackett reflected on her role as web content strategist in a blog post after a recent website migration, noting: "moving forward with a content strategy ... will ensure that University Libraries' website is useful, usable, and discoverable-now and in the future." 54

Yet, while the need for strategy is hard to dispute and librarians are theoretically well suited for web content strategy work, Blakiston \& Mayden noted that explicit organizational support for content strategy in libraries remained limited: "Despite the growing popularity of content strategy as a discipline, only a handful of libraries had hired staff dedicated to this role at the time we proposed adding a content strategist to our staff." 55

\section{CONCLUSION}

This article has traced the history of library adoption of web content management systems, the evolution of those systems, and the corresponding challenges as libraries have attempted to manage increasingly prolific content creation workflows across multiple, divergent CMS platforms.

\section{What is the Library Website, Anyway?}

While some variation would to be expected from institution to institution, largely missing from the conversation is agreement on the purpose and aim of the library website writ large. This lack of definition, together with the technological and growth-related issues already discussed, has doubtless contributed to the confusion. After all, how would we know if we are "building it right" if we are not sure what we are meant to be building in the first place? In response to this ambiguity, the following definition was proposed:

The library website is an integrated representation of the library, providing continuously updated content and tools to engage with the academic mission of the college/university. It is constructed and maintained for the benefit of the user. Value is placed on consumption of content by the user rather than production of content by staff. ${ }^{56}$

Effective Management of Library Web Content Requires Dedicated Resources and Clear Authority Inconsistent processes, disconnects between units, varying constituent goals, and vague or ineffective WCM governance structures are recurrent themes throughout the literature. As CMS applications have enabled broader access to web publishing, models of library web management 
have moved away from workflows structured around strictly technical tasks and permissions, and have instead migrated toward consensus-based, revolving committee structures. While greater involvement of subject matter experts has been noted as a positive earlier in this article, other challenges have also been acknowledged. McDonald, Haines, and Cohen stated: "In the context of web design and governance, consensus is a blocker to nimble, standards-based, user-focused action." ${ }^{57}$

\section{Library Website as an Integrated Representation of the Organization}

As previously discussed, web content governance issues often signal a lack of coordination, or even of unity, across an organization. Demsky stated, "We won't be fully successful until we see it as our website" (emphasis added).$^{58}$ Internal documentation from the University of Michigan Library emphasized the value of "publicly represent[ing] ourselves as one library," and stated:

The more people are provided with clear communication that shows our offerings and unique items are part of the ... Library-rather than confuse users by making primary attribution to a sub-library, collection, or service point-the more people will recognize and understand the library's tremendous, overall value. ${ }^{59}$

\section{Content Strategy and the Case for Library-Authored Content}

No CMS can, by itself, address the fact that authoring, editing, and publishing quality content is both a situated expertise and a significant, ongoing demand on staff time.

Each platform, resource, or database brings its own visual style, terminology, tone and functionality. They are all parts of the library experience, which in turn is one part of the student, research or teaching experience. An understanding of content strategy is critical if staff are to see the connections between their own content and the rest of the content delivered by the organization. ${ }^{60}$

Libraries must proactively embrace and employ best practices in content strategy and in writing for the web to effectively address considerations of literacy and to present a consistent voice for the organization. These practices position libraries to fully realize the promise of content management systems through embracing an ethos of library-authored content.

The authors define library-authored content as collectively owned and authored content that represents the organization as a whole. Library-authored content is:

- collaboratively planned, written, and edited with participation of both subject matter experts and domain experts (i.e., library staff with expertise in content strategy, web librarianship);

- carefully drafted to optimize for clarity within the context of the end-user;

- current, reviewed on a recurrent schedule, and regularly updated;

- consistent across the ecosystem of CMS applications and other platforms, including print materials and social media;

- compliant with industry standards (including but not limited to those related to accessibility), and with relevant internal brand standards; and

- centrally managed as the primary responsibility of one or more domain experts. 
In order for libraries to meet the ever-increasing demands on our resources to produce timely, user-centered content that advances our missions for supporting teaching, research, and learning, a cultural shift toward a more collective, collaborative model of web content management and governance is necessary. Content strategy provides a flexible, adaptable framework for libraries to more efficiently and effectively leverage the power of multiple CMS platforms, to present engaging on-point content, and to provide appropriate, scaffolded support for researchers at all levelswith a team of one or a team of many.

\section{ENDNOTES}

${ }^{1}$ Deane Barker, "What Web Content Management Is (and Isn't)," in Web Content Management (O'Reilly Media, Inc., 2016), sec. What Web Content Management Is (and Isn't), https://learning.oreilly.com/library/view/web-content-management/9781491908112/.

${ }^{2}$ Maira Bundza, Patricia Fravel Vander Meer, and Maria A. Perez-Stable, "Work of the Web Weavers: Web Development in Academic Libraries," Journal of Web Librarianship 3, no. 3 (September 15, 2009): 252, https://doi.org/10.1080/19322900903113233.

${ }^{3}$ Ruth Sara Connell, "Content Management Systems: Trends in Academic Libraries," Information Technology and Libraries 32, no. 2 (June 10, 2013): 43, https://doi.org/10.6017/ital.v32i2.4632.

${ }^{4}$ Connell, 46.

${ }^{5}$ Paul Browning and Mike Lowndes, "JISC TechWatch Report: Content Management Systems," 2001, 3, http://citeseerx.ist.psu.edu/viewdoc/summary?doi=10.1.1.15.9100.

${ }^{6}$ Camilla Fulton, "Library Perspectives on Web Content Management Systems," First Monday 15, no. 8 (July 15, 2010): sec. Review of literature, https://doi.org/10.5210/fm.v15i8.2631.

${ }^{7}$ Barker, "What Web Content Management Is (and Isn't)," sec. What Is A Content Management System?

${ }^{8}$ Browning and Lowndes, "JISC TechWatch Report," 4. Within a diagram outlining the major functions within the content life-cycle, they include the steps 'Review', 'Archive' and 'Dispose' steps which, in the experience and observations of the authors, are often overlooked in general library web practice.

${ }^{9}$ Barker, sec. Types of Content Management Systems.

${ }^{10}$ Laura B. Cohen, Matthew M. Calsada, and Frederick J. Jeziorkowski, "ScratchPad: A Quality Management Tool for Library Web Sites," Content and Workflow Management for Library Websites: Case Studies, 2005, 102-26, https://doi.org/10.4018/978-1-59140-533-7.ch005; Diane Dallis and Doug Ryner, "Indiana University Bloomington Libraries Presents Organization to the Users and Power to the People: A Solution in Web Content Management," Content and Workflow Management for Library Websites: Case Studies, 2005, 80-101, https://doi.org/10.4018/978-1-59140-533-7.ch004; Stephen Sottong, "Database-Driven Web Pages Using Only JavaScript: Active Client Pages," Content and Workflow Management for Library Websites: Case Studies, 2005, 167-85, https://doi.org/10.4018/978-1-59140-533- 
7.ch008; Ray Bailey and Tom Kmetz, "Migrating a Library's Web Site to a Commercial CMS within a Campus-wide Implementation," Library Hi Tech 24, no. 1 (January 1, 2006): 102-14, https://doi.org/10.1108/07378830610652130; Juan Carlos Rodriguez and Andy Osburn, "Developing a Distributed Web Publishing System at CSU Sacramento Library: A Case Study of Coordinated Decentralization," Content and Workflow Management for Library Websites: Case Studies, 2005, 51-79, https://doi.org/10.4018/978-1-59140-533-7.ch003; Barbara A. Blummer, "A Literature Review of Academic Library Web Page Studies," Journal of Web Librarianship 1, no. 1 (June 21, 2007): 45-64, https://doi.org/10.1300/J502v01n01_04; Robert Slater, "The Library Web Site: Collaborative Content Creation and Management," Journal of Web Librarianship 2, no. 4 (December 2008): 567-77, https://doi.org/10.1080/19322900802473928; Rebecca Blakiston, "Developing a Content Strategy for an Academic Library Website," Journal of Electronic Resources Librarianship 25, no. 3 (July 2013): 175-91, https://doi.org/10.1080/1941126X.2013.813295; Suzanne Chapman and Ian Demsky, "Taming the Kudzu: An Academic Library's Experience with Web Content Strategy," in Cutting-Edge Research in Developing the Library of the Future, ed. Bradford Lee Eden (Lanham, MD: Rowman \& Littlefield, 2015).

${ }^{11}$ Cohen, Calsada, and Jeziorkowski, "ScratchPad," 11; Rodriguez and Osburn, "Developing a Distributed Web Publishing System at CSU Sacramento Library," 76-77; Slater, "The Library Web Site," 57.

${ }^{12}$ Dallis and Ryner, "Indiana University Bloomington Libraries Presents Organization to the Users and Power to the People," 82.

${ }^{13}$ Holly Yu, ed., Content and Workflow Management for Library Web Sites: Case Studies (Hershey, PA: IGI Global, 2005), vi.

${ }^{14}$ Browning and Lowndes, "JISC TechWatch Report," 5.

${ }^{15}$ Michelle Mach, "Website Maintenance Workflow at a Medium-Sized University Library," Content and Workflow Management for Library Websites: Case Studies, 2005, 128, https://doi.org/10.4018/978-1-59140-533-7.ch006.

${ }^{16}$ Fulton, "Library Perspectives on Web Content Management Systems," sec. Review of literature.

${ }^{17} \mathrm{Yu}$, Content and Workflow Management for Library Web Sites, 2.

${ }^{18}$ Nora Hegarty and David Kane, "New Web Site, New Opportunities: Enforcing Standards Compliance within a Content Management System," Library Hi Tech 25, no. 2 (June 19, 2007): 278, https://doi.org/10.1108/07378830710755027.

${ }^{19}$ Elizabeth L. Black, "Selecting a Web Content Management System for an Academic Library Website," Information Technology and Libraries 30, no. 4 (December 1, 2011): 186, https://doi.org/10.6017/ital.v30i4.1869. 
${ }^{20}$ Dave Comeaux and Axel Schmetzke, "Accessibility of Academic Library Web Sites in North America: Current Status and Trends (2002-2012)," Library Hi Tech 31, no. 1 (March 1, 2013): 27, https://doi.org/10.1108/07378831311303903.

${ }^{21}$ David J. Comeaux, "Web Design Trends in Academic Libraries — A Longitudinal Study," Journal of Web Librarianship 11, no. 1 (January 2, 2017): 12, https://doi.org/10.1080/19322909.2016.1230031.

${ }^{22}$ Meredith Larson, “Even If You're Trying, You're Probably Not Writing for the Average American," Federal Communicators Network (blog), October 9, 2018, https://fedcommnetwork.org/2018/10/09/even-if-youre-trying-youre-probably-not-writingfor-the-average-american/.

${ }^{23}$ Rebecca Blakiston, Writing Effectively in Print and on the Web-A Practical Guide for Librarians (Rowman \& Littlefield, 2017), 110.

${ }^{24}$ National Adult Literacy Agency, "Plain English around the World," Simply Put, 2015, http://www.simplyput.ie/plain-english-around-the-world; Plain Language Action and Information Network, General Services Administration, United States Government, "Home | Plainlanguage.Gov," plainlanguage.gov, accessed February 1, 2019, https://www.plainlanguage.gov/.

${ }^{25}$ Danielle Skaggs, "My Website Reads at an Eighth Grade Level: Why Plain Language Benefits Your Users (and You)," Journal of Library \& Information Services in Distance Learning, 2016, 2, https://doi.org/10.1080/1533290X.2016.1226581.

${ }^{26}$ Black, “Selecting a Web Content Management System for an Academic Library Website,” 185.

${ }^{27}$ Kim Guenther, “Content Management Systems as 'Silver Bullets,'” Online 30, no. 4 (2006): 55.

28 Paul Browning and Mike Lowndes, “Content Management Systems: Who Needs Them?,” Ariadne, no. 30 (2002): sec. The Issue, http://www.ariadne.ac.uk/issue30/techwatch.

${ }^{29}$ Guenther, “Content Management Systems as 'Silver Bullets,'” 54.

${ }^{30}$ Guenther, 56.

${ }^{31}$ Michael Seadle, “Content Management Systems,” Library Hi Tech 24, no. 1 (January 1, 2006): 5, https://doi.org/10.1108/07378830610652068.

${ }^{32}$ Blakiston, “Developing a Content Strategy for an Academic Library Website,” 176.

${ }^{33}$ Chapman and Demsky, "Taming the Kudzu," 25.

${ }^{34}$ Bundza, Meer, and Perez-Stable, "Work of the Web Weavers," 256.

${ }^{35}$ Edward Iglesias, "Winning the Peace: An Approach to Consensus Building When Implementing a Content Management System," in Content Management Systems in Libraries: Case Studies, ed. Bradford Lee Eden (Scarecrow Press, 2008), 177. 
${ }^{36}$ Kristy Newton and Michelle Riggs, “Everybody's Talking but Who's Listening? Hearing the User's Voice above the Noise, with Content Strategy and Design Thinking," VALA2016 Conference, January 1, 2016, 1, https://ro.uow.edu.au/asdpapers/536.

${ }^{37}$ Emily G. Morton-Owens, "Editorial and Technological Workflow Tools to Promote Website Quality," Information Technology and Libraries 30, no. 3 (September 2, 2011): 91, https://doi.org/10.6017/ital.v30i3.1764.

${ }^{38}$ A. Paula Wilson, Library Web Sites: Creating Online Collections and Services (Chicago: American Library Association, 2004), 4.

${ }^{39}$ Chapman and Demsky, "Taming the Kudzu," 35.

${ }^{40}$ Morton-Owens, “Editorial and Technological Workflow Tools to Promote Website Quality," 97.

${ }^{41}$ Blakiston, Writing Effectively in Print and on the Web - a Practical Guide for Librarians, 6.

42 Scott W. H. Young, "Principle 1: Create Shareable Content," Library Technology Reports 52, no. 8 (November 18, 2016): 11-12.

${ }^{43}$ Susan Goodwin et al., "CMS/CMS: Content Management System/Change Management Strategies," Library Hi Tech 24, no. 1 (January 2006): 55-56, https://doi.org/10.1108/07378830610652103.

${ }^{44}$ Fulton, “Library Perspectives on Web Content Management Systems," sec. Discussion.

${ }^{45}$ Young, “Chapter 1. Principle 1," 12.

${ }^{46}$ Kristina Halvorson, "Understanding the Discipline of Web Content Strategy," Bulletin of the American Society for Information Science \& Technology 37, no. 2 (January 2011): 23-25, https://doi.org/10.1002/bult.2011.1720370208; Anne Haines, "Web Content Strategy: What Is It, and Why Should I Care?," InULA Notes 27, no. 2 (December 18, 2015): 11-15, https://scholarworks.iu.edu/journals/index.php/inula/article/view/20672/26734; U.S. Department of Health \& Human Services, “Content Strategy Basics,” usability.gov, January 24, 2016, https://www.usability.gov/what-and-why/content-strategy.html.

${ }^{47}$ Browning and Lowndes, “Content Management Systems,” sec. The Issue.

${ }^{48}$ Stuart Hales, "Providing Content Strategy Services," Information Outlook (Online); Alexandria 17, no. 6 (December 2013): 8.

${ }^{49}$ Kyle M. L. Jones and Polly-Alida Farrington, "WordPress as Library CMS," American Libraries; Chicago 42, no. 5/6 (June 2011): 34.

${ }^{50}$ Claire Rasmussen, "Do It Like a Librarian: Ranganathan for Content Strategists « Brain Traffic Blog," BrainTraffic Blog, June 13, 2012, https://web.archive.org/web/20120613173955/http://blog.braintraffic.com/2012/06/do-itlike-a-librarian-ranganathan-for-content-strategists/. 
${ }^{51}$ Rebecca Blakiston and Shoshana Mayden, "How We Hired a Content Strategist (And Why You Should Too)," Journal of Web Librarianship 9, no. 4 (2015): 196, https://doi.org/10.1080/19322909.2015.1105730.

52 Blakiston and Mayden, 197.

53 Ilka Datig, "Revitalizing Library Websites and Social Media with Content Strategy: Tools and Recommendations," Journal of Electronic Resources Librarianship 30, no. 2 (2018): 63-64, https://doi.org/10.1080/1941126X.2018.1465511.

${ }^{54}$ Karen Hackett, "What Is a Web Content Strategist?," Library News, October 17, 2016, https://sites.psu.edu/librarynews/2016/10/17/whats-a-web-content-strategist/.

55 Blakiston and Mayden, “How We Hired a Content Strategist (And Why You Should Too)," 196.

${ }^{56}$ Courtney McDonald, Anne Haines, and Rachael Cohen, "From Consensus to Expertise: Rethinking Library Web Governance," ACRL TechConnect (blog), November 2, 2015, https://acrl.ala.org/techconnect/post/from-consensus-to-expertise-rethinking-library-webgovernance/.

${ }^{57}$ McDonald, Haines, and Cohen.

58 Ian Demsky, "Lessons from My First Year as Web Content Strategist," Library Tech Talk (blog), August 7, 2014, https://www.lib.umich.edu/blogs/library-tech-talk/lessons-my-first-yearweb-content-strategist.

${ }^{59}$ University of Michigan Library, “Editorial Style and Best Practices,” January 23, 2019, sec. Library Branding.

${ }^{60}$ Newton and Riggs, “Everybody’s Talking but Who’s Listening?,” 12. 